\title{
Islet autoantibodies, nationality and gender: a multinational screening study in first-degree relatives of patients with Type I diabetes
}

\author{
A. J.K. Williams, P.J. Bingley, W.P.T.Moore, E.A.M. Gale and the ENDIT Screening Group
}

Diabetes and Metabolism, Division of Medicine, University of Bristol, Bristol, UK

\section{Abstract}

Aims/hypothesis. First-degree relatives of patients with Type I (insulin-dependent) diabetes mellitus diagnosed at 20 years of age or under were screened for islet cell antibodies (ICA) in the course of recruitment to an international diabetes prevention trial. Our aim was to evaluate the influence of age, gender, proband characteristics and nationality on the prevalence of ICA and co-existence of autoantibodies to GAD, IA-2 and insulin.

Methods. A central laboratory screened samples from 10326 non-diabetic relatives who were aged less than 40 years, from eight European countries for ICA. Antibodies to GAD and IA-2 were measured in all samples with ICA of $10 \mathrm{JDF}$ units or more.

Results. Overall, $8.9 \%$ of relatives had ICA of $10 \mathrm{JDF}$ units or more, $3.8 \%$ with ICA of $20 \mathrm{JDF}$ units or more. Of 921 relatives with ICA of $10 \mathrm{JDF}$ units or more, $29 \%$ had co-existing antibodies to GAD or IA- 2 or both. ICA of $10 \mathrm{JDF}$ units or more were more prevalent in males $(10.8 \%)$ than females $(7.3 \%)$. ICA with GAD or IA-2 antibodies or both were also more common in males $(3.4 \%)$ than females $(1.9 \%)$ and in relatives under 20 years of age (3.5\% vs $1.5 \%)$. Multiple regression analysis showed nationality to be a determinant of ICA of $10 \mathrm{JDF}$ units or more but not of ICA of 20 JDF units or more or of ICA with co-existing islet antibodies, and confirmed the importance of age and gender as determinants of islet autoimmunity.

Conclusions/interpretation. Relatives from different European countries have similar rates of islet autoimmunity despite wide variation in the background incidence of childhood diabetes, and male excess is equally evident in all populations. The male excess of ICA and islet autoimmunity over 10 years of age reflects the higher male incidence of Type I diabetes in this age group, and suggests that boys may be more likely than girls to develop islet autoimmunity during adolescence. [Diabetologia (2002) 45: 217223]

Keywords Type I diabetes, gender, nationality, prediction, ICA, GAD, insulin, IA-2 autoantibodies.
Received: 9 August 2001 and in revised form: 16 October 2001

* On behalf of the ENDIT Screening Group

Corresponding author: Prof. E.A.M.Gale, Medical School Unit, Southmead Hospital, Bristol BSI05NB, UK, e-mail: edwingale@bristol.ac.uk

Abbreviations: ENDIT, European Nicotinamide Diabetes Intervention Trial; IA-2, protein tyrosine phosphatase IA-2; ICA, islet cell autoantibodies; IAA, insulin autoantibodies; IDS, Immunology of Diabetes Society; JDF, Juvenile Diabetes Foundation
Family members have an increased risk of developing Type I (insulin-dependent) diabetes mellitus, and testing for multiple islet autoantibodies can achieve sensitive and specific identification of those who are destined to develop the disease [1]. The European Nicotinamide Diabetes Intervention Trial (ENDIT) is a multinational placebo-controlled trial which aims to evaluate the ability of high-dose nicotinamide to prevent Type I diabetes in first-degree relatives at high risk of the disease. Eligibility for ENDIT was based on two confirmed ICA positive samples, at least one having a level of 20 JDF units or above. Re- 
Table 1. Characteristics of the non-diabetic relatives screened for ICA in the central ENDIT laboratory. Representative standardised incidence figures were obtained from data published by the EURODIAB ACE Study Group [4]

\begin{tabular}{|c|c|c|c|c|c|c|c|c|c|c|c|}
\hline \multirow[t]{2}{*}{ Country } & \multirow[t]{2}{*}{ Number } & \multirow[t]{2}{*}{ Male } & \multicolumn{8}{|c|}{ Age (years) } & \multirow{2}{*}{$\begin{array}{l}\text { Standardised } \\
\text { incidence per } \\
100000 \text { per year }\end{array}$} \\
\hline & & & $0-4$ & $5-9$ & $10-14$ & $15-19$ & $20-24$ & $25-29$ & $30-34$ & $35-39$ & \\
\hline Austria & 722 & 308 & 26 & 45 & 86 & 105 & 50 & 72 & 169 & 169 & $9.1(8.5-9.8)$ \\
\hline Greece & 463 & 191 & 22 & 73 & 81 & 36 & 24 & 33 & 81 & 113 & $9.5(8.5-10.5)$ \\
\hline Hungary & 1740 & 796 & 116 & 277 & 290 & 185 & 88 & 124 & 241 & 419 & $8.9(8.2-9.5)$ \\
\hline Norway & 1403 & 661 & 65 & 239 & 213 & 212 & 102 & 70 & 199 & 303 & $21.2(19.3-23.1)$ \\
\hline Turkey & 632 & 274 & 15 & 97 & 118 & 100 & 48 & 49 & 91 & 114 & \\
\hline Total & 10326 & 4690 & 537 & 1785 & 1846 & 1298 & 601 & 641 & 1451 & 2167 & \\
\hline
\end{tabular}

cruitment of 552 trial entrants was achieved by screening more than 40000 first-degree relatives from 21 countries in Europe, Canada and the USA [2]. In many cases relatives were screened for ICA in their home countries, and eligibility was confirmed in the central reference laboratory. The central laboratory was however responsible for primary screening for ICA of all samples from first-degree relatives from eight European countries, and these results form the basis of the present analysis.

Standardised screening of this large group of firstdegree relatives gave us the opportunity to identify and compare characteristics influencing islet autoimmunity that might escape detection in smaller studies. ENDIT is well placed to compare populations in these respects because similar trials in the USA do not permit the analysis of national differences [3]. Our aim was therefore to evaluate the influence of age, gender, proband characteristics and nationality on the prevalence of ICA and co-existence of autoantibodies to GAD, IA-2 and insulin. We compared the prevalence of islet autoimmunity in first-degree relatives from countries with widely varying background rates of childhood diabetes, to establish whether relatives from different parts of Europe have similar susceptibility, and to develop improved strategies for screening and intervention to prevent Type I diabetes in our continent.

\section{Subjects and methods}

Subjects. Sera were obtained from 10326 non-diabetic first-degree relatives of patients with Type I diabetes who were diagnosed at 20 years or under and whose details of age at sampling, gender, and relationship to diabetic proband were known, as was the age of diagnosis of the proband. The study cohort was 3977 parents, 5368 siblings and 981 offspring. All probands required insulin treatment within 12 months of diagnosis. Only those countries where primary ICA screening was done by the central laboratory were included in the study. National groups participating in this analysis came from Austria, Greece, Hungary, Norway, Poland, Russia, Turkey and the
UK. Scotland, England and Northern Ireland participated as independent centres in the study but have been analysed as a single group. Characteristics of the relatives from each country are shown in Table 1 together with the standardised age-adjusted incidence of Type I diabetes diagnosed under 15 years of age, which is available for six participating countries [4].

ICA-screening assay. Islet cell autoantibodies were measured by indirect immunofluorescence $[5,6]$. Sera were incubated on $4 \mu \mathrm{m}$ acetone-fixed, frozen sections of pancreas from normal human donors of type "O" blood group, for $30 \mathrm{~min}$ at room temperature. The sections were washed in $10 \mathrm{mmol} / \mathrm{l}$ phosphate buffered saline (PBS) $\mathrm{pH} 7.4$ and incubated for 20 min with sheep anti-human $\mathrm{IgG}, \mathrm{A}, \mathrm{M}$ (H \& L) FITC conjugate (The Binding Site, Birmingham, UK) diluted in PBS. After washing, the sections were mounted and observed under a fluorescence microscope (DMR, Leica, Germany). All sections were observed in a blinded fashion and assigned an arbitrary intensity score from 0 to 7 . Each screening assay included the 5 sera used as standards in the quantification assay and two sera with high, medium, low or negative ICA levels to act as internal controls.

ICA quantification. All samples with an intensity score of 1 or greater in the screening assay were re-assayed in a quantification assay [6], while those samples with an intensity score of 1 less than one were considered negative. Samples included in the quantification assay were retrospectively titrated by means of doubling dilutions in PBS. Local standard sera calibrated to $6,11,19,45$ and 66 JDF units were included in each assay. The $\log _{2}$ endpoint titres of the test samples were converted to JDF units from the polynomial regression standard curve of $\log _{2}$ JDF units versus $\log _{2}$ endpoint titre of the standard sera. The threshold of detection for ICA was 6 JDF units. Each quantification assay included two internal controls with high, medium, low or negative ICA. Overall assay performance was monitored by the inclusion of 3 coded "external" quality control samples in every 100 samples screened. The inter-assay co-efficient of variation $(\mathrm{CV})$ of the ICA assay was $51 \%$ at $14 \mathrm{JDF}$ units, $35 \%$ at $38 \mathrm{JDF}$ units and $22 \%$ at $60 \mathrm{JDF}$ units. The ICA assay achieved $81 \%$ sensitivity with $86 \%$ specificity in the First Immunology of Diabetes Society (IDS) Combined Antibody Workshop [7].

Tissue from five pancreases was used as substrate during the course of the study. To maintain consistency, substrate from each new pancreas was evaluated in parallel with substrate from the previous pancreas by measuring ICA on a panel of 140 samples. These included sera from 109 adult blood 
Table 2. The prevalence (\% (95\%-CI)) of ICA $\geq 10$ JDF units alone and with co-existing islet antibodies in the non-diabetic relatives according to age and nationality. Antibodies to GAD and IA-2 were measured in all relatives, while antibodies to insulin were measured only in those aged less than 20 years

\begin{tabular}{lcccc}
\hline Country & \multicolumn{2}{c}{$<20$ years of age } & \multicolumn{2}{c}{$\geq 20$ years of age } \\
\cline { 2 - 3 } & ICA alone & ICA $+\geq 1 \mathrm{Ab}$ & $7.2(5.0-10.0)$ & ICA $+\geq 1 \mathrm{Ab}$ \\
\hline Austria & $5.7(3.2-9.3)$ & $2.7(1.1-5.5)$ & $8.1(6.3-10.2)$ & $1.5(0.6-3.1)$ \\
UK & $5.8(4.4-7.5)$ & $3.9(2.8-5.3)$ & $8.4(5.3-12.5)$ & $0.8(0.1-2.1)$ \\
Greece & $3.3(1.3-6.7)$ & $2.8(1.0-6.1)$ & $6.0(4.5-7.7)$ & $1.9(1.1-3.1)$ \\
Hungary & $4.1(2.9-5.7)$ & $3.0(2.0-4.4)$ & $8.8(6.7-11.2)$ & $1.2(0.5-2.3)$ \\
Norway & $5.1(3.6-6.9)$ & $4.1(2.8-5.8)$ & $6.7(5.4-8.2)$ & $1.6(1.0-2.4)$ \\
Poland & $4.7(3.8-5.8)$ & $4.1(3.3-5.2)$ & $6.3(3.4-10.6)$ & $1.9(0.5-4.9)$ \\
Russia & $3.3(1.6-6.0)$ & $3.6(1.8-6.4)$ & $10.9(7.6-15.0)$ & $2.3(0.9-4.7)$ \\
Turkey & $10.3(7.2-14.1)$ & $3.6(1.9-6.3)$ & $7.5(6.8-8.3)$ & $1.5(1.2-2.0)$ \\
\hline Total & $5.1(4.5-5.8)$ & $3.7(3.2-4.4)$ &
\end{tabular}

donors, 3 healthy volunteers, and 28 first-degree relatives (19 with ICA). Of these samples, all 8 found to have ICA of 20 JDF units or more on the original pancreas substrate were found to have ICA of $20 \mathrm{JDF}$ units or more on substrate from the other pancreases. Furthermore, of 8 additional samples found to have ICA of $20 \mathrm{JDF}$ units or more on substrate from any other pancreas, only 1 had ICA of less than $10 \mathrm{JDF}$ units on the original pancreas substrate.

$G A D$ and $I A-2_{\text {ic }}$ autoantibody assays. All samples with ICA of $10 \mathrm{JDF}$ units or more were assayed for GAD and IA- $2_{\text {ic }}$ autoantibodies with radiobinding assays, using in vitro transcribed and translated human ${ }^{35}$ S-GAD ${ }_{65}$, or ${ }^{35}$ S-IA-2 ${ }_{\text {ic }}$ as label [8]. Immune complexes were isolated with protein A sepharose (Amersham Pharmacia Biotech UK, Little Chalfont, Buckinghamshire, UK). Samples were initially screened using a combined GAD and IA-2 antibody assay [9, 10, 11], following the same protocol as the individual antibody assays except that sera were incubated with $15000 \mathrm{cpm}$ of both ${ }^{35} \mathrm{~S}-\mathrm{GAD}_{65}$ and ${ }^{35} \mathrm{~S}-\mathrm{IA}-2_{\text {ic }}$. Results for the combined antibody assay were expressed in units derived from a standard curve consisting of 8 doubling dilutions of serum from a first-degree relative of a patient with Type I diabetes containing IA-2 and GAD antibodies with serum from a healthy volunteer. Those samples with a combined antibody level above the lowest standard (0.4 units) were re-assayed separately for GAD and IA-2 antibodies. The threshold selected for the combined assay would not have excluded any samples identified as showing raised GAD and IA-2 antibodies in a screening study of 1028 schoolchildren [12]. Samples assayed for GAD and IA- $2_{\text {ic }}$ antibodies were considered positive if they had levels above the 97.5th centile of 2860 schoolchildren. The inter-assay CV of the combined antibody assay was $22 \%$ at 0.9 units and $19 \%$ at 23 units, of the GAD antibody assay was $20 \%$ at 6.2 units and $7.8 \%$ at 24 units, and of the IA- 2 antibody assay was $13 \%$ at 2 units and $19 \%$ at 31 units. The GAD antibody assay achieved $91 \%$ sensitivity with $99 \%$ specificity, and the IA-2 antibody assay $74.4 \%$ sensitivity with $99 \%$ specificity in the First IDS Combined Antibody Workshop [7].

Insulin autoantibody assay. All samples from relatives under 20 years of age with ICA levels of $10 \mathrm{JDF}$ units or more were assayed for insulin autoantibodies as previously described [13], using a format similar to that used for measuring GAD and IA-2 antibodies. Immune complexes were isolated using protein A sepharose. Bound counts for each sample were calculated after subtraction of background counts, and results were expressed in arbitrary units derived from a standard curve. Sera with insulin binding above 0.4 units were tested in a competition assay in which each sample was incubated with label in the presence of excess unlabelled insulin (Humulin, Lilly, Basingstoke, Hampshire, UK). Specific bound counts were converted into arbitrary units as described above. Samples assayed for insulin autoantibodies were considered positive if they had levels above the 97.5 th centile of 2860 schoolchildren. The inter-assay CV of the IAA assay was $21 \%$ at both 0.7 units and 1.7 units. The assay achieved $58 \%$ sensitivity with $99 \%$ specificity on the samples included in the First IDS Combined Antibody Workshop [7].

Statistical analyses. Multiple logistic regression was used to determine the influence on ICA levels and co-existence of other islet autoantibodies of age, gender, nationality, age of proband at diagnosis and relationship to the proband. Age at testing and age of the proband were modelled in 5-year bands. The age of the proband at diagnosis was not known for 273 relatives, and for these the median age of relatives tested in that country was used in the analysis. The model was built in stages following the general strategy for model selection suggested by Collett [14]. First, univariate analysis was used to identify variables individually predictive of ICA of $10 \mathrm{JDF}$ units or more, of $20 \mathrm{JDF}$ units or more or ICA of $10 \mathrm{JDF}$ units or more with co-existing IA-2 or GAD antibodies (stage 1). Those variables found to be significant at the $10 \%$ level were then included in the multivariate model (stage 2). Each variable was then excluded in turn to examine whether, in the presence of other variables, they continued to be predictive of autoantibodies. This procedure was continued until the exclusion of any variable would have resulted in a significant change in model fit $(p<0.10$, as defined by a change in $-2 \log L)$. Variables excluded after stage 1 were then added to this multivariate model in order to assess whether, in the presence of other significant variables, they became significant predictors $(p<0.10)$ of autoantibodies (stage 3 ). Finally interactions between variables retained at the end of stage 3 were examined and included if found significant at the $5 \%$ level. Other comparisons were performed using chi square $\left(\chi^{2}\right)$ analysis, and results were considered significant at the $5 \%$ level. Analyses were performed using the Statistics Package for Social Sciences (SPSS, Chicago, Ill., USA).

\section{Results}

The prevalence of ICA and co-existing islet antibodies in the non-diabetic, first-degree relatives from the participating countries is shown in Table 2. The 


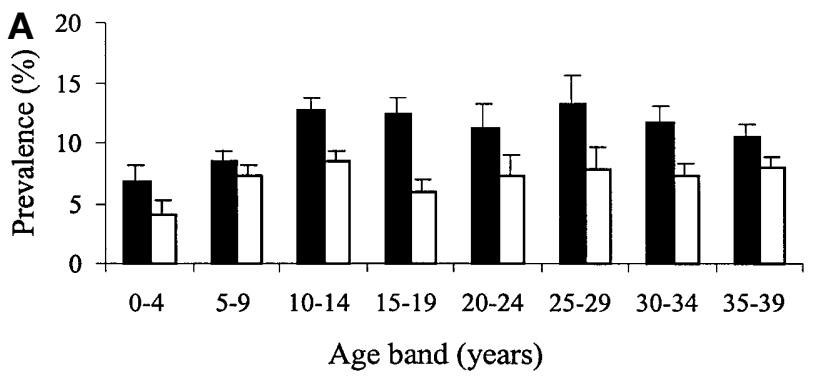

B

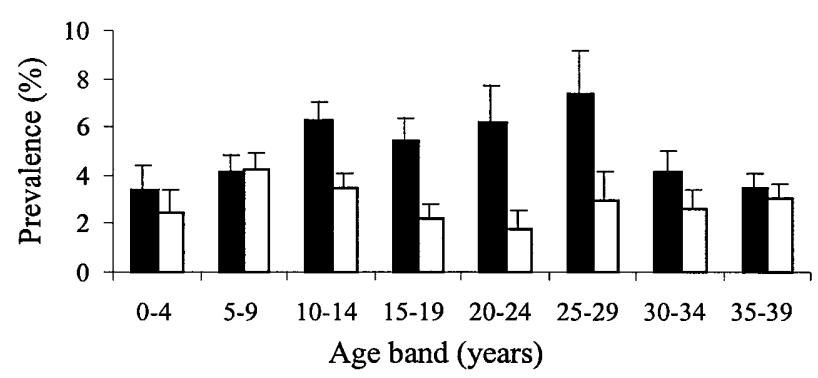

Fig. 1(A-D). A (left, upper panel) Prevalence of ICA $\geq 10$ JDF units and $\mathbf{B}$, (left, lower panel) ICA $\geq 20$ JDF units in 10326 first degree relatives screened for ENDIT in the central laboratory according to age and gender. $\mathbf{C}$ (right, upper panel) The prevalence of co-existing antibodies to GAD or IA-2 or both and $\mathbf{D}$ (right, lower panel) co-existing antibodies to insulin according to age and gender. Islet autoimmunity is more prevalent in males $(\square)$ than in females $(\square)$ over 10 years of age. Error bars represent SEM

overall prevalence of ICA of 10 JDF units or more was $8.9 \%$ and varied significantly between countries $(p=0.002)$. ICA of $20 \mathrm{JDF}$ units or more were present in $3.8 \%$ of relatives, while multiple antibody markers, ie. GAD or IA-2 antibodies or both in association with ICA of $10 \mathrm{JDF}$ units or more, indicative of high risk of progression, were found in $2.6 \%$.

The prevalence of ICA of 10 JDF units or more was dependent on age up to 15 years of age $(p<0.0001)$ but remained stable thereafter $(p=0.99)$. Of 537 relatives under 5 years of age, 30 (5.6\%) had ICA of $10 \mathrm{JDF}$ units or more compared to 141 of $1785(7.9 \%)$ of those aged 5 to 9 years, and 197 of $1846(10.7 \%)$ aged 10 to 14 years. The prevalence in 5-year age bands from 15-40 years varied between 8.8 and $9.5 \%$. The prevalence of ICA of 20 JDF units or more showed a similar trend and 3.0\% of children under 5 years of age, $4.2 \%$ of those aged 5 to 9 years, and $4.9 \%$ of those aged 10 to 14 years have ICA at this level $\left(\chi^{2}\right.$ for trend $\left.4.2, p=0.04\right)$ compared with $3.2 \%$ to $4.4 \%$ in older age groups $\left(\chi^{2}\right.$ for trend $0.97, p=0.33$ ).

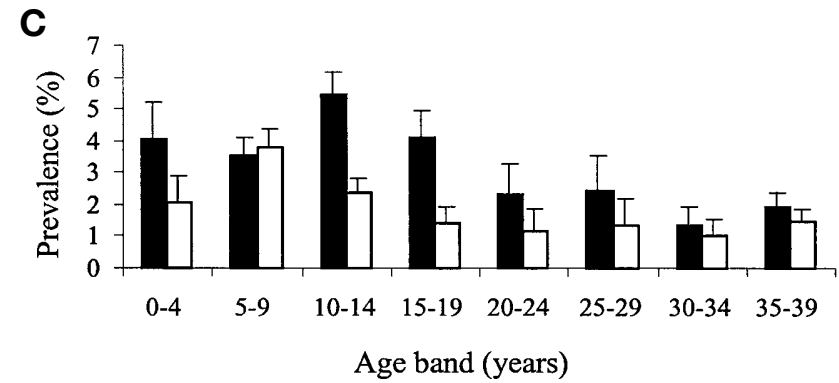

D

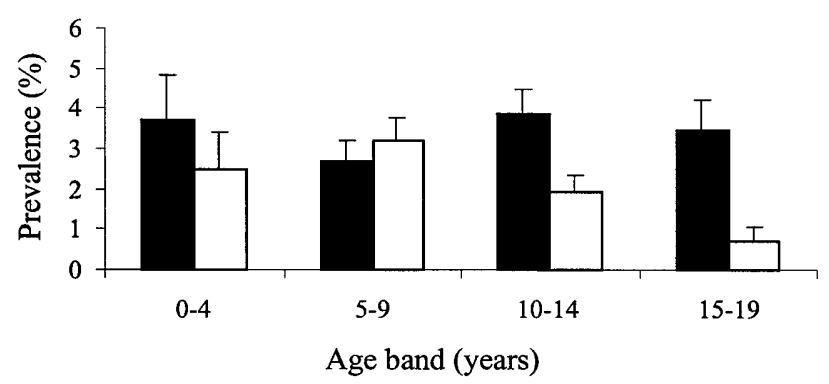

As expected, age strongly influenced the prevalence of ICA of 10 JDF units or more with co-existing antibodies, and $3.5 \%$ of relatives under 20 years of age had ICA of $10 \mathrm{JDF}$ units or more with co-existing GAD or IA-2 antibodies or both compared to $1.5 \%$ of older relatives $(p<0.0001)$. Co-existing GAD antibodies were found in a higher proportion of relatives under 20 years of age with ICA of 10 JDF units or more $(36 \%)$ than of older relatives $(15 \%$, $p<0.0001)$ and the same was true for co-existing IA2 antibodies ( $29 \%$ vs $6.2 \%, p<0.0001)$.

ICA showed a strong association with male gender (Fig. 1). Of 4690 male relatives, 508 (10.8\%) had ICA of $10 \mathrm{JDF}$ units or more compared to 413 of 5636 $(7.3 \%)$ female relatives $(p<0.0001)$. This male bias was also true for ICA of $20 \mathrm{JDF}$ or more, with 226 $(4.8 \%)$ male relatives with ICA above this level compared to $170(3.0 \%)$ female relatives $(p<0.0001)$. The prevalence of ICA of $10 \mathrm{JDF}$ units or more with co-existing GAD or IA-2 antibodies or both was also higher in male than female relatives $(3.4 \%$ vs $1.9 \%$, $p<0.0001$ ). Of the relatives with ICA of $10 \mathrm{JDF}$ units or more, the proportion of males and females having co-existing GAD antibodies was similar $(27 \%$ vs $24 \%$ ) but co-existing IA-2 antibodies were found in a higher proportion of males $(22 \%)$ than females $(14 \%)(p=0.002)$. In those under 20 years of age, insulin autoantibodies were present in a similar proportion of male and female relatives with ICA of $10 \mathrm{JDF}$ units or more (32\% vs $29 \%$ ).

The prevalence of ICA of 20 JDF units or more and of ICA with antibodies to GAD or IA-2 or both was influenced by the relationship to the proband, 
Table 3. Relative risk ( $95 \%-\mathrm{CI})$ for islet autoantibodies in multivariate analysis

\begin{tabular}{|c|c|c|c|}
\hline & $\begin{array}{l}\text { Relative risk for ICA } \geq \\
10 \mathrm{JDF} \text { units }\end{array}$ & $\begin{array}{l}\text { Relative risk for ICA } \geq \\
20 \mathrm{JDF} \text { units }\end{array}$ & $\begin{array}{l}\text { Relative risk for ICA }+\geq 1 \text { other } \\
\text { islet autoantibody marker }\end{array}$ \\
\hline $\begin{array}{l}\text { Nationality } \\
\text { Austria } \\
\text { UK } \\
\text { Greece } \\
\text { Hungary } \\
\text { Norway } \\
\text { Poland } \\
\text { Russia } \\
\text { Turkey }\end{array}$ & $\begin{array}{l}p=0.005) \\
1 \\
1.13(0.83-1.54) \\
0.91(0.59-1.4) \\
0.88(0.64-1.21) \\
1.14(0.83-1.57) \\
0.99(0.74-1.32) \\
0.91(0.59-1.39) \\
1.59(1.12-2.27)\end{array}$ & & \\
\hline $\begin{array}{l}\text { Age at testing } \\
<5 \mathrm{yr} \\
5-9 \mathrm{yr} \\
10-14 \mathrm{yr} \\
15-19 \mathrm{yr} \\
20-24 \mathrm{yr} \\
25-29 \mathrm{yr} \\
30-34 \mathrm{yr} \\
35-39 \mathrm{yr}\end{array}$ & $\begin{array}{l}(p=0.05) \\
1 \\
1.38(0.93-2.05) \\
1.86(1.25-2.78) \\
1.50(0.98-2.29) \\
1.51(0.94-2.43) \\
1.65(0.98-2.81) \\
1.43(0.83-2.46) \\
1.38(0.79-2.40)\end{array}$ & & $\begin{array}{l}(p<0.0001) \\
1 \\
1.17(0.68-2.02) \\
1.28(0.75-2.19) \\
0.88(0.49-1.59) \\
0.55(0.25-1.21) \\
0.60(0.28-1.30) \\
0.40(0.20-0.79) \\
0.55(0.31-0.99)\end{array}$ \\
\hline $\begin{array}{l}\text { Gender } \\
\text { Female } \\
\text { Male }\end{array}$ & $\begin{array}{l}(p<0.0001) \\
1 \\
1.58(1.37-1.81)\end{array}$ & $\begin{array}{l}(p<0.0001) \\
1 \\
1.59(1.30-1.95)\end{array}$ & $\begin{array}{l}(p=0.0001) \\
1 \\
1.65(1.28-2.12)\end{array}$ \\
\hline $\begin{array}{l}\text { Proband age } \\
<5 \mathrm{yr} \\
5-9 \mathrm{yr} \\
10-14 \mathrm{yr} \\
15-20 \mathrm{yr}\end{array}$ & $\begin{array}{l}(p=0.03) \\
1 \\
1.21(0.99-1.48) \\
1.26(1.02-1.55) \\
1.35(1.0-1.81)\end{array}$ & & \\
\hline $\begin{array}{l}\text { Relationship to proband } \\
\text { Offspring } \\
\text { Sibling } \\
\text { Parent }\end{array}$ & $\begin{array}{l}(p=0.054) \\
1 \\
1.59(0.98-2.57) \\
1.36(1.03-1.81)\end{array}$ & $\begin{array}{l}(p=0.07) \\
1 \\
1.10(0.78-1.55) \\
0.84(0.58-1.22)\end{array}$ & \\
\hline
\end{tabular}

but that of ICA of 10 JDF units or more was not. Both ICA of 20 JDF units or more and ICA of 10 JDF units or more with coexisting antibodies were most common in siblings and least common in parents. Of the 5368 siblings, $4.3 \%$ had ICA of $20 \mathrm{JDF}$ units or more and $3.3 \%$ had ICA of $10 \mathrm{JDF}$ units or more with co-existing antibodies compared with $4.0 \%$ and $3.0 \%$ respectively in 981 offspring and $3.2 \%$ and $1.5 \%$ in parents $(p=0.02$ and $p<0.0001)$. Neither ICA concentrations nor the prevalence of ICA with other autoantibodies varied according to the age of the proband at diagnosis.

Multiple logistic regression, however, showed that nationality, gender, age at testing, relationship to the proband and the age of the proband at diagnosis were independent determinants of ICA of $10 \mathrm{JDF}$ units or more $(p<0.01)$ (Table 3$)$. For higher levels of ICA ( $\geq 20$ JDF units) only gender and relationship to the proband were found to be significant $(p<0.01)$, while ICA of 10 JDF or more with co-existing antibodies to IA-2 or GAD were influenced only by gender and age at testing.

\section{Discussion}

ICA measurement was done in a single laboratory using rigorous quality assurance procedures on samples from 10326 non-diabetic first-degree relatives of patients with Type I diabetes from eight European countries. Overall, $8.9 \%$ were found to have ICA of $10 \mathrm{JDF}$ units or more at screening, and $3.8 \%$ had levels of $20 \mathrm{JDF}$ units or more, the threshold for eligibility to the trial. The prevalence of ICA of $10 \mathrm{JDF}$ units or more in the eight European countries varied from $7.5 \%$ in Russia to $13.6 \%$ in Turkey. Because the study cohorts differed with respect to age, gender and proband characteristics, multiple regression analysis was used to examine the influence of these factors.

Age was a weak determinant of ICA. The prevalence of ICA of $10 \mathrm{JDF}$ units or more in children increased in each 5-year band up to the age of 15 years and remained stable thereafter, and a similar trend was seen with ICA of $20 \mathrm{JDF}$ units or more. Age was strongly correlated with the presence of additional autoantibodies conferring a high risk of progression to disease, with co-existing GAD or IA-2 antibodies in $3.5 \%$ of relatives aged less than 20 years as against $1.5 \%$ of those who were between 20 and 40 years of 
age. This is consistent with previous studies showing that ICA carry a higher risk of progression to diabetes in younger relatives $[15,16,17]$.

ICA were strongly associated with male gender (Fig 1, Table 3), whether considered alone at thresholds of both 10 and $20 \mathrm{JDF}$ units or more, or in combination with other islet autoantibodies. The strength of these associations varied with age. Thus, the prevalence of ICA of $10 \mathrm{JDF}$ units or more with co-existing GAD, IA-2 or insulin autoantibodies was similar in both sexes up to 10 years of age, but nearly 2.5 times as high in males as in females between 10 and 20 years of age. The increased prevalence of islet autoimmunity in adolescent males reflects the male gender bias in Type I diabetes presenting over the age of $15[18,19]$. Furthermore, it prompts reconsideration of the common assumption that ICA rarely appear for the first time after the age of 10 [20], since this cross-sectional study showed an increase in each 5 -year age band up to 15 years of age. This suggests that islet autoimmunity continues to develop or mature $[21,22]$ in male relatives as they approach puberty and could explain why a male gender bias in diabetes incidence only becomes evident in some populations after 15 years of age, but prospective studies would be required to confirm this. The inference that single or multiple antibody responses could appear in male relatives at any time up to 15 years of age has important implications for the design of future intervention trials, and suggests that repeated screening could be indicated in adolescence even when earlier tests are negative.

Low, but not high, levels of ICA were weakly associated with nationality after correction for the influence of gender, age and proband characteristics. Stringent quality control procedures were undertaken for this study, but national samples were usually tested in batches and assay variation at low levels of ICA is one possible explanation for the discrepancy. We would attach more weight to the observation that ICA of 20 JDF units or more or multiple antibodies were not associated with nationality, implying that relatives in different European countries have similar rates of islet autoimmunity despite wide variation in the background incidence of childhood diabetes. This observation could appear surprising, given that reported rates of familial diabetes vary widely across Europe [23], although it should be noted that comparable risk estimates are not available for these populations. It is possible that the rate of progression to diabetes could vary between autoantibody positive first-degree relatives in high and low risk environments even though their lifetime risk of disease development could be similar.

In summary, markers associated with a high risk of progression to diabetes were strongly associated with male gender and young age but were not influenced by nationality and did not seem to relate to back- ground risk of diabetes within a population. The finding that the prevalence of islet antibody markers is similar in first-degree relatives from eight European countries suggests they have similar susceptibility to the initiation of islet autoimmunity. The male excess in islet autoimmunity only appeared after 10 years of age and corresponds to the increased risk of diabetes in older males. This cross-sectional observation suggests that boys are more likely than girls to develop islet autoimmunity after early childhood.

ENDIT Screening Group: Austria: E. Schober, B. Rami; Greece: C. Bartsocas, A. Gerasimidou-Vazeou, I. Thymelli; Hungary: M. Györko, L. Madácsy, A. Luczay, B. Bornemisza, G. Soltész; Norway: G. Joner, K. Skjold Rønningen, K. DahlJørgensen; Poland: I. Kinalska, H. Dziatkowiak, R. Wasikowa, D. Kielczewska-Mrozikiewicz, A. Mrozikiewicz; Russia: E. Schwartz, Y. Vaykhonsky; Turkey: I. Satman, M. T. Yilmaz, G. Yillar, S. Darcan, Z. Osar; UK: D. Carson, O. McGlone, S. Greene, A. Wilson, K. Robertson.

Acknowledgements. We are grateful to C. Rogers for statistical advice, H. Gillmor for collating data and K. Tejle, M. Shattock, S. Cox and A. Norcross for technical assistance. We thank the local investigators from participating countries and the families for their contribution to this study. Central co-ordination of ENDIT is funded by the Juvenile Diabetes Foundation and Novo Nordisk. Previous funding was obtained from the European Community.

\section{References}

1. Bingley PJ, Williams AJK, Gale EAM (1999) Optimized autoantibody-based risk assessment in family members. Diabetes Care 22: 1796-1801

2. Gale EAM (1996) Theory and practice of nicotinamide trials in pre-type 1 diabetes. J Pediatr Endocrinol Metab 9: 375-379

3. Yu L, Cuthbertson DD, Maclaren N et al. (2001) Expression of GAD65 and islet cell antibody (ICA512) autoantibodies among cytoplasmic ICA + relatives is associated with eligibility for the Diabetes Prevention Trial -Type 1. Diabetes 50: 1735-1740

4. EURODIAB ACE Study Group (2000) Variation and trends in incidence of childhood diabetes in Europe. Lancet 355: 873-876

5. Bottazzo GF, Florin-Christensen A, Doniach D (1974) Islet-cell antibodies in diabetes mellitus with polyendocrine disease. Lancet ii: $1279-1283$

6. Bonifacio E, Bingley PJ, Dean BM et al. (1990) Quantification of islet-cell antibodies and prediction of insulin-dependent diabetes. Lancet 335: 147-149

7. Verge CF, Stenger D, Bonifacio E et al. (1998) Combined use of autoantibodies (IA-2 autoantibody, GAD autoantibody, insulin autoantibody, cytoplasmic islet cell antibodies) in type 1 diabetes: combinatorial islet autoantibody workshop. Diabetes 47: 1857-1866

8. Bingley PJ, Bonifacio E, Williams AJK, Genovese S, Bottazzo GF, Gale EAM (1997) Prediction of IDDM in the general population. Strategies based on combinations of autoantibody markers. Diabetes 46: 1701-1710

9. Bonifacio E, Lampasona V, Genovese S, Ferrari M, Bosi E (1995) Identification of protein tyrosine phosphatase-like IA2 (islet cell antigen 512) as the insulin-dependent diabe- 
tes-related $37 / 40 \mathrm{~K}$ autoantigen and a target of islet-cell antibodies. J Immunol 155: 5419-5426

10. Dittler J, Seidel D, Schenker M, Ziegler AG (1998) GADIA2-combi determination as first line screening for improved prediction of type 1 diabetes in relatives. Diabetes 47: 592-597

11. Wiest-Ladenburgher U, Hartmann R, Hartmann U, Berling K, Bohm BO, Richter W (1997) Combined analysis and single step detection of $\mathrm{GAD}_{65}$ and IA2 autoantibodies in IDDM can replace the histochemical islet cell antibody test. Diabetes 46: 565-571

12. Marciulionyte D, Williams AJK, Bingley PJ, Urbonaite B, Gale EAM (2001) A comparison of the prevalence of islet autoantibodies in children from two countries with differing incidence of diabetes. Diabetologia 44: 16-21

13. Williams AJK, Bingley PJ, Bonifacio E, Palmer JP, Gale EAM (1997) A novel micro-assay for insulin autoantibodies. J Autoimmun 10: 473-478

14. Collett D (1994) Modelling survival data in medical research, 1st edn. Chapman and Hall, London

15. Krischer JP, Schatz D, Riley WJ et al. (1993) Insulin and islet cell autoantibodies as time-dependent covariates in the development of insulin-dependent diabetes: a prospective study in relatives. J Clin Endocrinol Metab 77: 743-749

16. Bingley PJ, The ICARUS Group (1996) Interactions of age, islet cell antibodies, insulin autoantibodies, and first- phase insulin response in predicting risk of progression to IDDM in ICA positive relatives. Diabetes 45: 1720-1728

17. Riley WJ, Maclaren NK, Krischer J et al. (1990) A prospective study of the development of diabetes in relatives of patients with insulin-dependent diabetes. N Engl J Med 323: 1167-1172

18. Gale EAM, Gillespie KM (2001) Diabetes and gender. Diabetologia 44: 3-15

19. Weets I, Van Autreve J, Van der Auwera BJ et al. (2001) Male-to-female excess in diabetes diagnosed in early adulthood is not specific for the immune-mediated form nor is it HLA-DQ restricted: possible relation to increased body mass index. Diabetologia 44: 40-47

20. Leslie RDG, Elliott RB (1994) Early environmental events as a cause of IDDM. (evidence and implications). Diabetes 43: 843-850

21. Yu L, Rewers M, Gianani R et al. (1996) Antiislet autoantibodies usually develop sequentially rather than simultaneously. J Clin Endocrinol Metab 81: 4264-4267

22. Ziegler AG, Hummel M, Schenker M, Bonifacio E (1999) Autoantibody appearance and risk for development of childhood diabetes in offspring of parents with type 1 diabetes. The 2-year analysis of the German BABYDIAB study. Diabetes 48: 460-468

23. EURODIAB ACE Study Group (1998) Familial risk of Type I diabetes in European children. Diabetologia 41: 1151-1156 